\title{
'Practical autonomy' entitles some animals to rights
}

\section{Basic rights stem from the ability to desire, to act intentionally and to have a sense of self.}

Sir - In your Opinion article "Rights, wrongs and ignorance" (Nature 416, 351; 2002), you urge scientists and lawyers to challenge the arguments for the basic rights of great apes and other non-human animals that I made in my books Rattling the Cage (Profile Books/Perseus; 2000) and the forthcoming Drawing the Line (Perseus; 2002). You say that some cognitive scientists will challenge my interpretation of the scientific evidence. But others will not. Those who do will find themselves boxing not with me, but with many eminent primatologists and cognitive scientists, for it is their interpretations I adopt.

I am more qualified to argue about law. You refer to those who claim that only beings able to assert rights can have them, so therefore neither young children nor non-human animals can have rights, but should instead be protected. Presumably you would extend this argument to any human beings unable to assert their rights. Yet even the philosopher Carl Wellman, a major proponent of that idea, calls this extrapolation monstrous. Unlike claim rights, such immunity rights as bodily integrity and freedom from slavery can belong to human children, infants, the very retarded, the profoundly senile and the insane. And thank goodness for that, as it is the weakest humans who are in most need of legal protection from exploitation.

You challenge my argument that the precautionary principle, a staple of environmental law, should encourage judges and legislators to recognize basic rights for some non-human animals, and say that the "immense benefits of biomedical experimentation for human health" should be factored in. This misunderstands both my argument for the basic liberty rights of non-human animals and the precautionary principle itself.

I say that a minimum level of autonomy — the abilities to desire, to act intentionally and to have some sense of self, whatever the species - is sufficient to justify the basic legal right to bodily integrity. I call this level "practical autonomy" and maintain that a creature who demonstrates it, whether an adult chimpanzee, bonobo, gorilla, orang-utan, Atlantic bottlenosed dolphin or human, is entitled to this basic legal right. One may reject my premise. But I argue that this rejection on utilitarian grounds undermines the foundation for most basic human rights. We don't enslave people or deprive them of their right to bodily integrity because we think we will benefit if we do.

The precautionary principle comes into play when one is not as sure as one would like that a being has practical autonomy. The strength of that being's claim to bodily integrity turns on how uncertain we are. I argue against both stringent and loose applications of the precautionary principle to the question of which non-human animals are entitled to basic legal rights.

Under the moderate application I urge, African grey parrots and African elephants are entitled to basic rights. Based on what is known, dogs and honeybees are not. But who knows what exciting breakthroughs tomorrow's research may bring?

Steve Wise

Center for the Expansion of Fundamental Rights, Inc., 896 Beacon Street, Boston,

Massachusetts 02215, USA

\section{Cancer centre didn't shoot the messenger}

Sir - In your Opinion article "Media studies for scientists" (Nature 416, 461; 2002), you imply that scientists at the Fred Hutchinson Cancer Research Center failed to provide information to The Seattle Times and then cried "bad journalism". You advise that "Rather than shooting the messengers, scientists should take them to one side and give them the real story".

Researchers at the Fred Hutchinson Cancer Research Center enjoy a good relationship with the media, frequently spending considerable time discussing and explaining our science to reporters. If you had checked with us you would have discovered that, in this case as well, we logged many hours of one-to-one interviews between researchers at the centre and the reporters for The Seattle Times.

We will continue these efforts to work with the news media on our campaign to inform the general public about the importance of clinical trials. We hope that reporters will invest the time to explore and discuss fully the subject about which they are writing.

It is also noteworthy that the accusation of bad journalism came not from a scientist but from a journalist for The Wall Street Journal.

\section{Lee Hartwell}

Fred Hutchinson Cancer Research Center, 1100 Fairview Avenue North, Seattle, Washington 98109-1024, USA

\section{A theory can be falsified or tested. Faith cannot}

Sir - Your news story "Evolution critics seek role for unseen hand in education" (Nature 416, 250; 2002) identifies an important issue in science teaching: that of the way science is taught versus the concepts that are taught as science. The proponents of 'intelligent design' correctly point out the value of challenging scientific theory. Such challenges are an essential component of science if theories are not to become dogma. Science curricula the world over should embrace this principle, and science should be taught as a dynamic field in which new ideas are continually being tested and revised.

Scientific progress has been made by examining many wondrous and fantastic ideas, but educators must make it abundantly clear that not all fantastic ideas represent sound science. This is central in determining the subject matter of science curricula. The longstanding and powerful attempt to integrate creationism into science classes is an excellent example of politics blurring the boundary of the subject.

Creationists argue that since evolution is not completely proven, it is important to present a competing theory, to let students decide for themselves. Scientists oppose such ideas for one simple reason: creationism, in any form, is not science. By including a supernatural being, or an 'intelligent design' concept, creationists exclude their ideas from the domain of science because these are neither testable nor falsifiable - two criteria that are crucial to scientific method.

Any alternative to evolutionary theory must follow the methods of science, being based on testable, falsifiable hypotheses. Perhaps one way in which creationism can be used constructively in science education would be as a tool to illustrate how not to carry out science.

\section{Mark W. Silby}

Center for Adaptation Genetics and Drug Resistance, Department of Molecular Biology and Microbiology, Tufts University School of Medicine, 136 Harrison Avenue, Boston, Massachusetts 02111, USA 